DOI 10.31509/2658-607x-2019-2-3-1-11

УДК 581.52:528.88

ОСНОВНЫЕ ЗАКОНОМЕРНОСТИ ПРОСТРАНСТВЕННОЙ ЛОКАЛИЗАЦИИ РАЗЛИЧНЫХ ТИПОВ ХВОЙНЫХ И ХВОЙНО-ШИРОКОЛИСТВЕННЫХ ЛЕСОВ СЕВЕРНОГО МАКРОСКЛОНА ЗАПАДНОГО КАВКАЗА ПО МАТЕРИАЛАМ ДИСТАНЦИОННОГО ЗОНДИРОВАНИЯ ЗЕМЛИ

(C) 2019 г.

\author{
Р.Х. Пшегусов*, Ф.А. Темботова, Ю.М. Саблирова
}

Институт экологии горных территорий им. А.К. Темботова РАН

Россия, 360051, КБР, г. Нальчик, ул. И. Арманд, 37 а

*E-mail: p_rustem@inbox.ru

Поступила в редакцию 10.06.2019

В работе приводится сравнительная характеристика параметров пространственной локализации хвойных и хвойно-широколиственных лесов в различных ландшафтноклиматических условиях Западного Кавказа. В ходе исследования поставлена задача определения параметрических переменных, отражающих наиболее значимые факторы распространения хвойных и хвойно-широколиственных лесов Западного Кавказа, на основе синтеза полевых и дистанционных данных. Для проведения исследований и сбора материала в 2016-2018 году было заложено 76 пробных площадей на территории Западного Кавказа. В результате исследований приводится типологическая схема хвойных и хвойношироколиственных лесов района исследований, выделено 13 типов леса, распределенных по 7 группам. Древостои в изученных типах леса преимущественно разновозрастные, многоярусные, высокосомкнутые, средне- и высокополнотные. Сделаны выводы о высокой достоверности модели пространственного распределения на основании параметрических значений дискриминантных функций и средних значений предикторов.

Ключевые слова: Западный Кавказ, хвойные леса, данные дистанционного зондирования, пространственный анализ.

Одним из вопросов в исследованиях лесных экосистем Северо-Западного Кавказа является отсутствие актуального картографирования хвойных и хвойно-широколиственных лесов на всем протяжении Северного Кавказа (Темботова и др., 2012; Комарова, 2017) в целом, и Западного Кавказа в частности. Выявление факторов, характеризующих пространственное распределение растительных сообществ - задача, актуальная как с практической (для мониторинга и сохранения биоразнообразия на всех уровнях, планирования хозяйственных мероприятий и т.д.), так и с теоретической (установление экологических параметров распространения видов, закономерностей формирования растительных сообществ) точек зрения.

В ходе данного исследования была поставлена цель: определение параметрических переменных, отражающих наиболее значимые факторы распространения хвойных и хвойно- 
широколиственных лесов Западного Кавказа, на основе синтеза полевых и дистанционных данных.

\section{МАТЕРИАЛ И МЕТОДЫ}

Материал собран на экспедиционных маршрутах и пунктах постоянного наблюдения на территории северного отдела Кавказского государственного природного биосферного заповедника им. Х.Г. Шапошникова (далее Кавказский заповедник). На лесных участках в долине реки Малая Лаба и ее притоков проводились геоботанические описания и определялись таксационные характеристики древостоев. При проведении полевых исследований применяли традиционные в геоботанике методы исследования и нормативы, принятые в лесной таксации (Сукачев, 1961; 1972; Загреев и др., 1992; Неронов, 2002). Классификацию лесного покрова по результатам геоботанических описаний проводили на основе доминантного подхода. Тип леса в статье рассматривался как тип биогеоценоза (Сукачев, 1964).

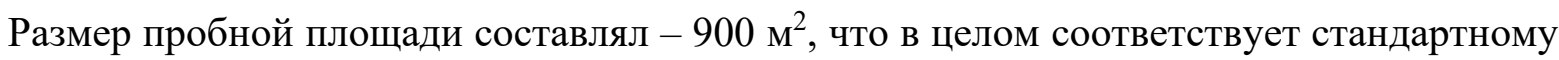
пикселю мультиспектральной съемки Landsat. Всего на территории Западного Кавказа за периоды - 2012-2015 и 2017-2018 гг. было обследовано 78 пробных площадей.

Для оценки параметров текущей пространственной локализации использовались сцены среднего пространственного разрешения Landsat 8 OLI/TRS от 13 сентября 2018 г. (ID сцены LC81730302018256LGN00), как наиболее близкого к периоду проведения исследований и не закрытого облаками, пространственный анализ и интерполяция результатов осуществлялась посредством регрессионного и дискриминантного анализов и моделей регрессионных/классификационных деревьев (Пузаченко, 2004). Для последующей классификации и моделирования типов леса нами был проведен дискриминантный анализ при оценочной вероятности встречаемости (строится на частоте встречаемости типов леса в обучающей выборке) с обратным пошаговым включением переменных при уровне F-критерия = 1. В целом высокие результаты правильного распознавания (в среднем 95.5\%), значения коэффициента регрессии и результаты построения классификационных деревьев указывают на высокую прогностическую способность как обучающей выборки, так и созданной интерполяционной модели. Подробнее методы исследования описаны в литературе, посвященной данной тематике (Барталев, 2006; Козлов и др, 2008; Исаев, Черненькова, 2009; Темботова, Пшегусов, Тлупова, 2012).

\section{РЕЗУЛЬТАТЫ И ОБСУЖДЕНИЕ}

В результате регрессионного анализа из 86 переменных дистанционного зондирования (Wood, 1996; Сандлерский, 2013; Fick, Hijmans, 2017; McNally et al., 2017), в совокупности характеризующих вегетационные, термодинамические составляющие и морфометрические 
характеристики рельефа, значимыми оказались 18 (табл. 1). Так же отметим высокое значение коэффициентов регрессии $\left(\mathrm{R}=0.73 ; \mathrm{R}^{2}=0.7114\right.$; накопленный $\left.\mathrm{R}^{2}=0.7144 ; \mathrm{F}(19.43)=2929.4\right)$, что указывает на высокую степень прогностической способности указанных переменных при моделировании пространственного распределения хвойных и хвойно-широколиственных лесов на территории исследования.

Таблица 1. Результаты регрессионного анализа

\begin{tabular}{|l|c|c|c|c|c|c|}
\hline \multicolumn{7}{|c|}{ Regression Summary: } \\
\hline & R $=0.73832891 ; R^{2}=0.711446645 ;$ & Adjusted R ${ }^{2}=0.71442738 ;$ & F $(19,430588)=2929.4$ \\
\hline Intercept & - & - & 9.684 & 3.243 & 2.986 & 0.003 \\
\hline SLOPE & -0.297 & 0.002 & -0.070 & 0.000 & -193.804 & 0.000 \\
\hline NDVI & -0.173 & 0.014 & -7.152 & 0.578 & -12.379 & 0.000 \\
\hline NDWI & 0.218 & 0.034 & 6.579 & 1.028 & 6.398 & 0.000 \\
\hline K & -0.271 & 0.020 & -10.730 & 0.786 & -13.653 & 0.000 \\
\hline TVI & -0.121 & 0.038 & -0.084 & 0.026 & -3.236 & 0.001 \\
\hline RVI & 0.182 & 0.021 & 0.454 & 0.051 & 8.855 & 0.000 \\
\hline TK & -0.030 & 0.002 & -0.015 & 0.001 & -19.193 & 0.000 \\
\hline SWIR2_R & -0.045 & 0.014 & -0.612 & 0.191 & -3.210 & 0.001 \\
\hline G_B & 0.122 & 0.010 & 10.789 & 0.928 & 11.630 & 0.000 \\
\hline DU & -0.243 & 0.012 & -0.043 & 0.002 & -20.141 & 0.000 \\
\hline REL & -0.025 & 0.002 & 0.000 & 0.000 & -12.496 & 0.000 \\
\hline LMI & 0.219 & 0.013 & 5.267 & 0.323 & 16.326 & 0.000 \\
\hline R_G & 0.100 & 0.011 & 4.809 & 0.532 & 9.037 & 0.000 \\
\hline TSAVI & 0.377 & 0.047 & 10.953 & 1.378 & 7.948 & 0.000 \\
\hline ASPECT & -0.010 & 0.002 & 0.000 & 0.000 & -6.632 & 0.000 \\
\hline VI7 & 0.020 & 0.007 & 1.255 & 0.470 & 2.669 & 0.008 \\
\hline W & 0.117 & 0.013 & 0.041 & 0.005 & 8.825 & 0.000 \\
\hline BR & 0.110 & 0.016 & 0.016 & 0.002 & 7.020 & 0.000 \\
\hline
\end{tabular}

Примечание: SLOPE - уклон, градусы; NDVI - Нормализованный разностный вегетационный индекс; NDWI Нормализованный разностный индекс содержания влаги в зеленой фитомассе; K - Энтропия Кульбака (мера структурной сложности системы, отражающей (Eout) и поглощающей (R) энергию); TVI - Tрансформированный вегетационный индекс; RVI - Относительный вегетационный индекс; TK - Температура излучающей поверхности, кельвин; SWIR2_R - Коротковолновой индекс красного спектра; G_B - Интенсивность фотосинтеза, транспирация; DU - Приращение внутренней энергии системы; REL - высота, м над уровнем моря; LMI Содержание влаги в зеленой фитомассе; R_G - Интенсивность фотосинтеза, чистая продукция; TSAVI Трансформированный почвенный вегетационный индекс; ASPECT - экспозиция склона, градусы; VI7 Инфракрасный вегетационный индекс; W - Содержание влаги в зеленой фитомассе (преобразование Kauth's Tasseled Cap); BR - Общая яркость, альбедо (преобразование Kauth's Tasseled Cap).

С целью первичной классификации нами построены общие регрессионные и классифицирующие деревья (ОР\&КД). Результаты отображения важности переменных в классификационном анализе (рис. 1) в целом соответствуют таковым в регрессионном, однако 
здесь значимыми оказались параметры рельефа (высота над уровнем моря и экспозиция склона), а из спектральных переменных - вегетационные индексы.

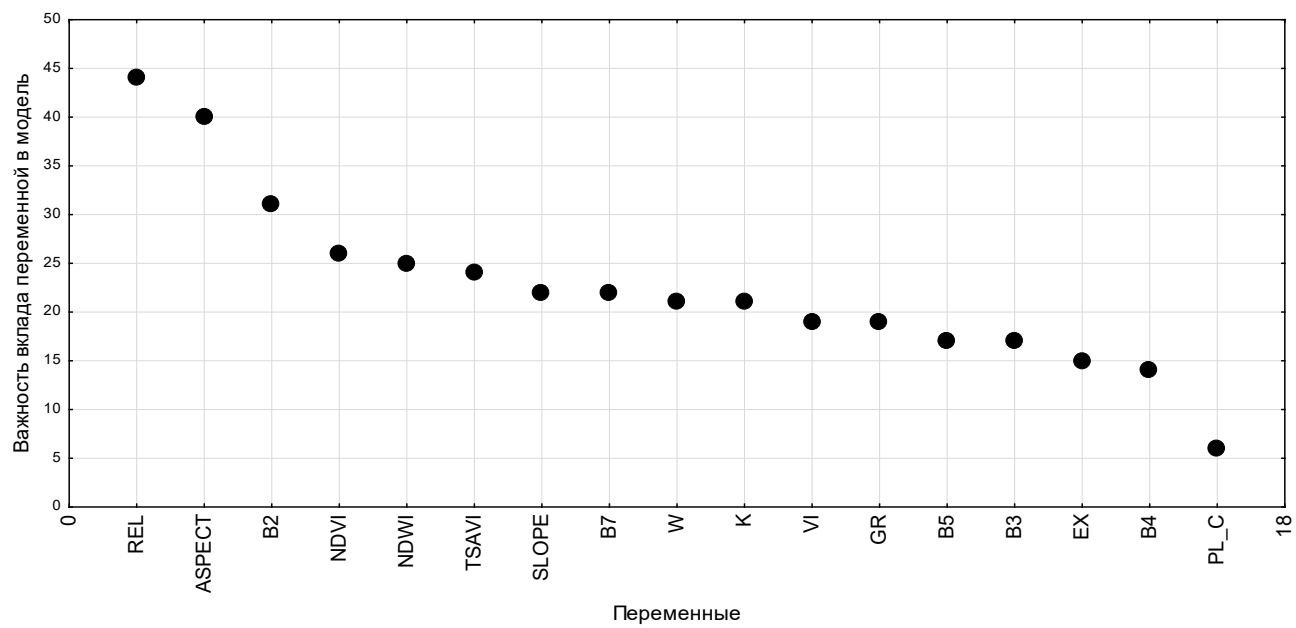

Рисунок 1. График вклада переменных в построение модели дерева классификации типов леса

По результатам обследований лесных участков на территории Восточного отдела Кавказского заповедника выделены 13 типов леса, которые распределены по 7 группам. Группа пихтарников разнотравных включает в себя буково-пихтовый кисличный II класса бонитета, буково-пихтовый мертвопокровный II класса бонитета, буково-пихтовый недотроговый II класса бонитета. В остове древостоя данной группы доминируют Abies nordmanniana (Steven.) Spach., Fagus orientalis Lipsky. Сомкнутость крон на разных участках варьирует в пределах 0.8-0.9. Подлесок представлен единичными экземплярами Sambucus nigra L., Corylus avellana L. Общее проективное покрытие (ОПП) напочвенного покрова составляет 50-60\%, за исключением буково-пихтового мертвопокровного, где травянистый ярус практически отсуствует.

В группе пихтарников папоротниковых выделен пихтарник папоротниковый II класса бонитета. В составе древостоя доминирует Abies nordmanniana (Steven.) Spach, во втором ярусе в незначительном встречаются Fagus orientalis Lipsky, Tilia begoniifolia Steven., Acer platanoides L., Picea orientalis (L.) Link. Сомкнутость крон составляет 0.8. Подлесок практически отсуствует. ОПП напочвенного покрова составляет 20-30\%.

В группе букняков разнотравных выделен 1 тип леса: елово-буковый кисличный I класса бонитета. В составе древостоя преобладают Fagus orientalis Lipsky, Picea orientalis (L.) Link. Сомкнутость крон древесного полога составляет 0.8. Подлесок отсутствует. ОПП напочвенного покрова составляет 15-20\%.

В группу букняков папоротниковых включены елово-буковый папоротниковый лес I класса бонитета, пихтово-буковый папоротниковый лес II класса бонитета. На лесных участках, представленных данной группой типов леса преобладают Fagus orientalis Lipsky, 
Picea orientalis (L.) Link. Единично отмечены Acer platanoides L., Alnus incana (L.) Moench, A. glutinosa (L.) Gaertn., Abies nordmanniana (Steven.) Spach. Сомкнутость крон составляет 0.8. Подлесок практически отсуствует. ОПП напочвенного покрова на разных участках варьирует в пределах 20-60\%.

Группа ельников папоротниковых представлена буково-еловым папоротниковым лесом II класса бонитета. На лесных участках данного типа леса преобладают Picea orientalis (L.) Link и Fagus orientalis Lipsky. Единично отмечен Alnus incana (L.) Moench, Abies nordmanniana (Steven.) Spach, Carpinus betulus L., Acer platanoides L. Сомкнутость крон древесного полога составляет 0.9. Подлесок не развит. ОПП напочвенного покрова $30 \%$.

Группа ельников разнотравных представлена буково-еловым мертвопокровным лесом II класса бонитета. Древесный ярус составляют Fagus orientalis Lipsky, Picea orientalis (L.) Link. Сомкнутость крон - 0.9. В составе подлеска отмечены Grossularia uva-crispa (L.) Mill., Ribes aureum Pursh, Euonymus europaeus L. ОПП напочвенного покрова 0-10\%.

Группа сосняков сложных включает в себя следующие типы леса: дубово-сосновый разнотравный, дубово-сосновый азалиевый, грабово-сосновый разнотравный, осиновососновый разнотравный. Древесный ярус образован Pinus sylvestrus L., также в его составе на разных участках преобладают Quercus robur L., Carpinus betulus L., Populus tremula L. Сомкнутость крон составляет 0.5-0.6. Подлесок образован Prunus spinosa L, Spiraea hypericifolia L, Rhododendron luteum Sweet., Corylus avellana L., Ribes aureum Pursh, Sambucus nigra L. ОПП напочвенного покрова в разных типах леса варьирует в пределах 5-80\%.

Для территории Кавказского заповедника К.Ю. Голгофской (1967) была разработана дробная классификационная лесотипологическая схема, включающая в том числе 24 типа леса, где в составе древостоев доминируют хвойные породы. Автор выделил группы: каменистые буко-пихтарники, пихтарники колхидскокустарниковые, пихтарники среднетравноовсяницевые, пихтарники вейниковые, пихтарники скальные, пихтарники саблевиднобуковые, пихтарники смешанношироколиственные, ельники каменистые, ельники моховые, ельники среднетравно-овсяницевые, сосняки вейниковые, сосняки злаковые, сосняки азалиевые, сосняки разнотравные, которые для территории Восточного отдела Кавказского заповедника нами не выявлены. Однако для изученного района в классификационной схеме приводятся группы ельников разнотравных, ельников папоротниковых. а также группа сосняков сложных, включающая в себя дубово-сосновый разнотравный, дубово-сосновый азалиевый, грабово-сосновый разнотравный, осиновососновый разнотравный типы леса, которые не приводятся в ранее проведенных исследования на территории Кавказского заповедника. Подробную классификационную типологическую схему пихтовых лесов Кавказа в своей работе приводит С.М. Бебия (2002). Автор выделяет 
группы пихтарников разнотравных, пихтарников папоротниковых. Которые также выявлены нами на территории исследуемого района. Также С.М. Бебия выделяет группы овсяницевых пихтарников, пихтарников с колхидским подлеском, разнотравных субальпийских пихтарников, которые нами не выявлены для территории бассейна р. Малая Лаба. По результатам наших исследований для территории Восточного отдела выделены следующие типы лесов с участием пихты Нордманна: буково-пихтовый кисличный, буково-пихтовый мертвопокровный, буково-пихтовый недотроговый, пихтово-буковый папоротниковый и пихтарник папоротниковый.

По выделенным группам типов леса и непосредственно по типам леса пространственные характеристики распределяются следующим образом.

Группа разнотравных пихтарников.

Буково-пихтовый кисличный II класса бонитета - из выделенных групп леса занимает наибольшую площадь (7604 га, 19.6\% от лесопокрытой площади), распространен в высотных пределах от 600 до 2200 м над ур. м., на склонах средней крутизны (15-20) северной и северозападной экспозиции.

Буково-пихтовый мертвопокровный II класса бонитета - занимает площадь около 350 га, на средней крутизны склонах $\left(20-27^{\circ}\right)$ восточной и юго-восточной экспозиции.

Буково-пихтовый недотроговый II класса бонитета - представлен на площади около 200 га, на южных и юго-восточных склонах средней крутизны (16-21º).

Группа папоротниковых пихтарников. В данной группе на изученной территории выделен один тип леса - пихтарник папоротниковый II класса бонитета, занимает около $12.5 \%$ от лесопокрытой площади, представлен на крутых склона (порядка $30^{\circ}$ ) северозападной экспозиции.

Группа разнотравных букняков. В этой группе на исследуемых участках выделен один тип леса - елово-буковый кисличный I класса бонитета, на площади около 5 тыс. га (13\%), на пологих и средней крутизны склонах (8-17º) западной экспозиции.

Группа папоротниковых букняков. Широко распространённая на Западном Кавказе группа типов леса, на исследуемом участке наряду с группой разнотравных пихтарников наиболее представлена по занимаемой площади (около 30\% от лесопокрытой площади).

Елово-буковый папоротниковый I класса бонитета - занимает около 6 тыс. га (16\%), представлен на выположенных склонах (в среднем $5^{\circ}$ ) западной и северо-западной экспозиции.

Пихтово-буковый папоротниковый II класса бонитета - распространен на площади 5100 га $(13 \%)$, на пологих склонах $\left(10^{\circ}\right)$ западной и юго-западной экспозиции. 
Группа папоротниковых ельников. Представлен одним типом леса - буково-еловыцй nапоротниковый II класса бонитета - занимает площадь 2.9 тыс. га (7.5\%), на пологих склонах $\left(9.8^{\circ}\right)$ южной экспозиции.

Группа разнотравных ельников, так же представлена одним типом леса - буковоеловый мертвопокровный II класса бонитета, занимающим небольшую площадь 179 га $(0.46 \%)$, на пологих склонах юго-восточной экспозиции.

Группа сосняков сложных представлена следующими типами леса:

Дубово-сосновый разнотравный - распространен на площади 643 га (1.66\%), на средней крутизны склонах $\left(22^{\circ}\right)$ южно-юго-восточной экспозиции.

Дубово-сосновый азалиевыци - занимает 339 га (0.87\%), на средней крутизны склонах (28) южной экспозиции.

Грабово-сосновый разнотравный - занимает около 3 тыс. га (7.8\%), на средней крутизны склонах $\left(17.5^{\circ}\right)$ восточной и юго-восточной экспозиции.

Осиново-сосновый разнотравный - распространен на площади 2.2 тыс. га (5.85\%) на средней крутизны склонах $\left(18^{\circ}\right)$ южной-юго-восточной экспозиции.

Наибольшую площадь среди выделенных типов леса в модели занимают буковопихтовый кисличный тип леса, наименее представлены мертвопокровные (буково-еловый и буково-пихтовый) типы (табл. 2).

Таблица 2. Площади основных типов хвойных и хвойно-широколиственных лесов

Кавказского заповедника

\begin{tabular}{|c|l|c|c|c|}
\hline \multirow{2}{*}{ № } & \multicolumn{1}{|c|}{ Тип леса } & \multicolumn{2}{|c|}{ Площадь } & $\begin{array}{c}\text { \% от } \\
\text { площади } \\
\text { лесов }\end{array}$ \\
\cline { 3 - 4 } & & пиксель & га & 0.46 \\
\hline 1 & Буково-еловый мертвопокровный II класса бонитета & 1992 & 179.28 & 0.45 \\
\hline 2 & Буково-еловый папоротниковый II класса бонитета & 32098 & 2888.82 & 7.45 \\
\hline 3 & Буково-пихтовый кисличный II класса бонитета & 84496 & 7604.64 & 19.62 \\
\hline 4 & $\begin{array}{l}\text { Буково-пихтовый мертвопокровный II класса } \\
\text { бонитета }\end{array}$ & 3882 & 349.38 & 0.90 \\
\hline 5 & Буково-пихтовый недотроговый II класса бонитета & 2244 & 201.96 & 0.52 \\
\hline 6 & Грабово-сосновый разнотравный & 33927 & 3053.43 & 7.88 \\
\hline 7 & Дубово-сосновый азалиевый & 3765 & 338.85 & 0.87 \\
\hline 8 & Дубово-сосновый разнотравный & 7153 & 643.77 & 1.66 \\
\hline 9 & Елово-буковый папоротниковый I класса бонитета & 69091 & 6218.19 & 16.05 \\
\hline 10 & Елово-буковый кисличный I класса бонитета. & 55936 & 5034.24 & 12.99 \\
\hline 11 & Осиново-сосновый разнотравный & 25201 & 2268.09 & 5.85 \\
\hline 12 & Пихтарник папоротниковый II класса бонитета. & 54145 & 4873.05 & 12.57 \\
\hline 13 & $\begin{array}{l}\text { Пихтово-буковый папоротниковый II класса } \\
\text { бонитета }\end{array}$ & 56673 & 5100.57 & 13.16 \\
\hline \multicolumn{2}{|l|}{ Всего } & 430603 & 38754 & 100 \\
\hline
\end{tabular}




\section{ЗАКЛЮЧЕНИЕ}

Таким образом по результатам полевых работ на территории Восточного отдела Кавказского заповедника выделено 13 типов леса, распределенных по 7 группам типов леса: ельники папоротниковые, ельники разнотравные, букняки папоротниковые, букняки разнотравные, пихтарники папоротниковые, пихтарники разнотравные, сосняки сложные. Древостои в изученных типах леса преимущественно разновозрастные, многоярусные, высокосомкнутые, средне- и высокополнотные.

Согласно построенной модели, площадь лесов с доминированием хвойных пород в районе исследований составляет 38.8 тыс. га (14\% от площади территории исследования). Они преимущественно приурочены к крутым (25-30 и больше) северным и западным склонам (6070\% площадей склонов данных экспозиций), в интервале высот от 1000 до 2000 м над ур. м.

В дальнейшем классификационная типологическая схема хвойных и хвойношироколиственных лесов Западного Кавказа будет дополняться и детализироваться. Так же полученные параметрические значения дискриминантных функций и средние значения предикторов дают основания использовать их в дальнейшем при распознавании и классификации типов леса снимков прошлого периода для формирования модели пространственно-временной динамики лесов Западного Кавказа.

\section{СПИСОК ЛИТЕРАТУРЫ}

Голгофская К.Ю. Типы буковых и пихтовых лесов бассейна р. Белой и их классификация // Труды Кавказского государственного заповедника. 1967. № 9. С. 157-284.

Барталев С.С. Разработка методики региональной экологической оценки состояния лесов по данным спутниковых наблюдений. Автореф. дисс. ... канд. техн. наук (спец. 25.00.34). M., 2006. $21 \mathrm{c}$.

Бебия С.М. Пихтовые леса Кавказа. М.: Изд-во МГУЛ, 2002. 237 с.

Загреев В.В., Сухих В.И., Швиденко А.З., Гусев Н.Н., Мошкалев А.Г. Общесоюзные нормативы для таксации лесов: Справочник. Москва: Колос, 1992. 495 с.

Исаев А.С., Черненькова Т.В. Мониторинг биоразнообразия лесов: подходы и результаты // Лесные ресурсы таежной зоны России: проблемы лесопользования и лесовосстановления. Петрозаводск, 30 сентября - 03. октября 2009 г. Петрозаводск: КарНЦ PAH, 2009. C. 60-62.

Козлов Д.Н., Пузаченко М.Ю., Федяева М.В., Пузаченко Ю.Г. Отображение пространственного варьирования свойств ландшафтного покрова на основе дистанционной информации и цифровой модели рельефа // Известия РАН. Серия географическая. 2008. № 4. C. $112-124$. 
Комарова А.Ф. Разнообразие темнохвойных лесов Северо-западного Кавказа и закономерности их пространственного распределения: Дисс. ... канд. биол. наук (спец. 03.02.01). M., 2017. 174 c.

Неронов В.В. Полевая практика по геоботанике в средней полосе европейской России: Методическое пособие. М.: Изд-во Центра охраны дикой природы, 2002. 139 с.

Пузаченко Ю.Г. Математические методы в экологических и географических исследованиях. М.: Академия, 2004. 408 с.

Сандлерский Р.Б. Термодинамические характеристики южно-таежных биогеоценозов на основе дистанционной информации (юг Валдайской возвышенности, Центрально-Лесной заповедник). Автореф. дисс. ... канд. биол. наук. М., 2013. 26 с.

Сукачев В.Н. Избранные труды. Том 1. Основы лесной типологии и биогеоценологии. Л.: Наука, 1972. 418 с.

Сукачев В.Н. Динамика лесных биогеоценозов // В кн.: Основы лесной биогеоценологии. М., 1964. С. 458-486.

Сукачев B.Н., Зонн C.B. Методические указания к изучению типов леса. М.: Изд-во АН CCCP, 1961. $144 \mathrm{c}$.

Темботова Ф.А., Пшегусов Р.Х., Тлупова Ю.М. Леса северного макросклона Центрального Кавказа (эльбрусский и терский варианты поясности) / Разнообразие и динамика лесных экосистем России. Кн. 1. М.: КМК, 2012. С. 227-251.

Fick S.E., Hijmans R.J. Worldclim 2: New 1-km spatial resolution climate surfaces for global land areas // International Journal of Climatology. 2017. No. 37. P. 4302-4315.

McNally A., Arsenault K., Kumar S., Shukla S., Peterson P., Wang S., Funk C., Peters-Lidard C.D., Verdin J.P. A land data assimilation system for sub-Saharan Africa food and water security applications // Scientific Data. 2017. No. 4. P. 170012.

Wood J. The Geomorphological Characterization of Digital Elevation Models. Ph.D. thesis, Leicester: University of Leicester, 1996.

\section{REFERENCES}

Bartalev S.S., Razrabotka metodiki regional'noj jekologicheskoj ocenki sostojanija lesov po dannym sputnikovyh nabljudenij Avtoref. diss. ... kand. tehn. nauk (Development of a methodology for regional environmental assessment of forest condition based on satellite observations. Candidate's biol. sci. thesis), Moscow, 2006. 21 p.

Bebija S.M., Pihtovye lesa Kavkaza (Caucasus fir forests), Moscow, Izd-vo MGUL, 2002, $237 \mathrm{p}$.

Fick S.E., Hijmans R.J., Worldclim 2: New 1-km spatial resolution climate surfaces for global land areas, International Journal of Climatology, 2017, No. 37, pp. 4302-4315. 
Golgofskaya K.Yu., Tipy bukovyh i pihtovyh lesov bassejna r. Beloj i ih klassifikacija (Types of beech and fir forests of the Belaya river basin and their classification), Trudy Kavkazskogo gosudarstvennogo zapovednika, 1967, No. 9, pp. 157-284.

Isaev A.S., Chernen'kova T.V., Monitoring bioraznoobrazija lesov: podhody i rezul'taty (Forest biodiversity monitoring: approaches and results), Lesnye resursy taezhnoj zony Rossii: problemy lesopol'zovanija i lesovosstanovlenija (Forest Resources of the Taiga Zone of Russia: Problems of Forest Management and Reforestation), Petrozavodsk, September 30 - October 03 2009, Petrozavodsk: KarNC RAN, 2009, pp. 60-62.

Komarova A.F., Raznoobrazie temnohvojnyh lesov Severo-zapadnogo Kavkaza $i$ zakonomernosti ih prostranstvennogo raspredelenija, Diss. ... kand. biol. nauk (Diversity of dark coniferous forests of the North-Western Caucasus and pattern of their spatial distribution), Moscow, $2017,174 \mathrm{p}$.

Kozlov D.N., Puzachenko M.Ju., Fedjaeva M.V., Puzachenko Ju.G., Otobrazhenie prostranstvennogo var'irovanija svojstv landshaftnogo pokrova na osnove distancionnoj informacii i cifrovoj modeli rel'efa (Mapping of spatial variation of landscape cover properties based on distance information and digital elevation model), Izvestija RAN. Serija geograficheskaja. 2008. No. 4. pp. 112-124.

McNally A., Arsenault K., Kumar S., Shukla S., Peterson P., Wang S., Funk C., Peters-Lidard C.D., Verdin J.P., A land data assimilation system for sub-Saharan Africa food and water security applications, Scientific Data, 2017, No. 4, p. 170012.

Neronov V.V., Polevaja praktika po geobotanike v srednej polose evropejskoj Rossii: Metodicheskoe posobie (Field practice in geobotany in Central European Russia: Methodical manual), Moscow: Izd-vo Centra ohrany dikoj prirody, 2002, 139 p.

Puzachenko Ju.G., Matematicheskie metody $v$ jekologicheskih $i$ geograficheskih issledovanijah (Mathematical methods in environmental and geographical research), Moscow: Akademija, 2004, 408 p.

Sandlerskij R.B., Termodinamicheskie harakteristiki juzhno-taezhnyh biogeocenozov na osnove distancionnoj informacii (jug Valdajskoj vozvyshennosti, Central'no-Lesnoj zapovednik) Avtoref. diss. ... kand. biol. nauk. (Thermodynamic characteristics of southern taiga biogeocenoses based on remote information (south of Valdai Upland, Central Forest Reserve), Moscow, 2013. 26 p.

Sukachev V.N. Dinamika lesnyh biogeocenozov, In: Osnovi lesnoi biogeocenologii, Moscow, 1964, pp. 458-486.

Sukachev V.N., Izbrannye trudy. Osnovy lesnoj tipologii i biogeocenologii (Selected Works. Basics of forest typology and biogeocenology), Leningrad: Nauka, 1972, 418 p. 
Sukachev V.N., Zonn S.V., Metodicheskie ukazanija k izucheniju tipov lesa (Guidelines for the study of forest types), Moscow: Izd-vo AN SSSR, 1961, 144 p.

Tembotova F.A., Pshegusov R.H., Tlupova Ju.M., Lesa severnogo makrosklona Central'nogo Kavkaza (jel'brusskij i terskij varianty pojasnosti) (Forests of the northern macroslope of the Central Caucasus (Elbrus and Terek variants of zonality)), In: Raznoobrazie i dinamika lesnyh jekosistem Rossii (Diversity and dynamics of forest ecosystems of Russia), Moscow: KMK, 2012, pp. 227-251.

Wood J., The Geomorphological Characterization of Digital Elevation Models. Ph.D. thesis, Leicester: University of Leicester, 1996.

Zagreev V.V., Suhih V.I., Shvidenko A.Z., Gusev N.N., Moshkalev A.G., Obshhesojuznye normativy dlja taksacii lesov: Spravochnik (All-Union regulations for forest taxation: a Handbook), Moscow: Kolos, 1992. 495 p.

\title{
THE MAIN REGULARITIES OF THE SPATIAL LOCALIZATION OF VARIOUS TYPES OF THE CONIFEROUS AND CONIFEROUS-DECIDUOUS FORESTS OF THE NORTH MACROSLOPE OF WESTERN CAUCASUS BY EARTH REMOTE SENSING MATERIALS
}

\author{
R.Kh. Pshegusov, F.A. Tembotova, Yu.M. Sablirova \\ Tembotov Institute of ecology of mountain territories RAS \\ I. Armand st. 37a, Nalchik, KBR, 360051, Russia \\ E-mail:p_rustem@inbox.ru \\ Received 10 June 2019
}

The paper presents a comparative description of the parameters of the spatial localization of the spatial localization parameters of coniferous and coniferous-deciduous forests in various landscape and climatic conditions of the Western Caucasus. In the course of the study, the task was set of determining parametric variables that reflect the most significant factors in the distribution of coniferous forests of the Western Caucasus, based on the synthesis of field and distance data. In 20162018, 76 trial plots were laid in the Western Caucasus for research and material collection. As a result of the research, a typological diagram of the coniferous and coniferous-deciduous forests of the research area is presented, 13 types of forests are allocated, distributed among 7 groups. Forest stands in the studied forest types are mainly of different ages, many-tiered, highly closed, medium and highdensity. Conclusions are made about the high reliability of the spatial distribution model based on the parametric values of discriminant functions and average values of predictors.

Key words: West Caucasus, coniferous forests, remote sensing data, spatial analysis.

Рецензент: к.б.н., с.н.с. Шевченко Н.Е. 